\title{
Dehumidification in an underground utility tunnel: field experiment and modeling
}

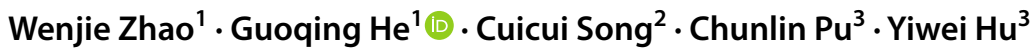

Received: 2 June 2021 / Accepted: 1 September 2021/Published online: 27 September 2021

(c) The Author(s), under exclusive licence to Springer Nature Switzerland AG 2021

\begin{abstract}
The recent rapid development of underground utility tunnels (UUT) in China reflects the government's resolve to improve the municipal service amid rapid urbanization. Although safety is of primary concern in the design and operation of the UUT, the moisture issue appears to be neglected. In the southern and eastern China, however, condensation in the UUT is noted and is believed to be responsible for the high rate of equipment failure and the deterioration of air quality inside the tunnel. To understand the moisture issue and its implications to the design and construction of the UUT, this study investigates the moisture balance in a section of the UUT in Suzhou city, eastern China. An experimental dehumidification study was carried out in a $200 \mathrm{~m}$ long $4.05 \mathrm{~m} \times 2.5 \mathrm{~m}$ cable compartment with the objective to identify major sources and their strengths. Two refrigeration dehumidifiers were used to control the relative humidity. The results show that the most significant moisture source was the outdoor air through ventilation (values dependent on the air change rates), followed by the open water evaporation $(\sim 4.195 \mathrm{~kg} / \mathrm{hr})$ inside the tunnel and the leakage from the neighboring unconditioned compartments. The concrete walls had a strong buffering effect, which was a strong source at the beginning of the dehumidification $(\sim 17.171 \mathrm{~kg} / \mathrm{hr})$. A mathematical model was developed that can predict the tunnel humidity fairly well. The results suggested that the dehumidification needs to be included in the design, construction, and operation of the future utility tunnel. This includes reserved spaces for moisture control systems, an operation strategy for dehumidification, covered drainage system, and quality construction and maintenance.
\end{abstract}

Keywords Urban Utility Tunnel $\cdot$ Dehumidification $\cdot$ Experiment $\cdot$ Modeling $\cdot$ Concrete walls $\cdot$ Moisture sources

\section{Introduction}

Traditionally, municipal pipelines are buried under roads and streets and are prone to damage. The repair is often expensive and impacts greatly on traffic and city service. In addition, the limited shallow underground space makes it difficult to accommodate the increasing number of modern pipelines [1]. Therefore, the urban utility tunnel (UUT) becomes an appealing alternative for sustainable

Guoqing He

guoqinghe@zju.edu.cn

1 College of Civil Engineering and Architecture, Zhejiang University, Hangzhou 310058, People's Republic of China

2 CCDI(SuZhou) Exploration \& Design Consultant CO, Ltd, Suzhou, Jiangsu 215123, People's Republic of China

3 Suzhou Utility Tunnel Development CO. Ltd, Suzhou, China development of the cities to accommodate pipelines for water supply, sewage, fuel oil, reclaimed water, gas, heat, power, communication, and other municipal utility services [2]. In China, the UUT normally accommodates two or more types of such pipelines [3].The unified planning, construction, and management of municipal public pipelines are implemented so as to realize the comprehensive development and utilization of urban road underground space and the intensive construction of municipal public pipelines and management [4].

Although the history of the underground tunnels can be dated back to the ancient roman times, modern UUT started around the mid-1850s in France [5].The world witnessed the rapid development of UUT in the late half of the twentieth century. Japan built more than $2,000 \mathrm{~km}$ of UUT in 80 cities as of 2018 [6]. In 2015, China started to promote the construction of UUT [4] and began to lead the world in terms of total length under construction [7]. As 
of 2020, China has achieved its target of $8,640 \mathrm{~km}$ UUT built or being built and another $12,000 \mathrm{~km}$ planned [8].

The UUT represents an important infrastructure and serves as the "invisible lifeline" of urban operation. However, amid the development of the UUT in China, its maintenance faces new challenges. Among them are the ventilation requirements and the condensation issues. Ventilation is an essential strategy to ensure the air quality and safety in the tunnel [9]. In China, the Technical Code [3] specifies the minimum ventilation rates for various cabins of the UUT. The minimum air change rates are 6 times per hour for the gas cabin and 2 times per hour for all the other cabins. The corresponding emergency ventilation rates are 12 and 6 times per hour for the gas cabin and all the other cabins, respectively. For cabins with heat sources, higher ventilation rates are needed to keep the temperature of the tunnel below $40^{\circ} \mathrm{C}$ for the safety purpose. In China, three common ventilation schemes are used: mechanical exhaust ventilation with passive inlet, mechanical supply ventilation with passive outlet, and mechanical supply and exhaust ventilation [10].Ventilation constitutes an important part of the operation cost. A number of studies have been devoted to study the design of the ventilation system $[11,12]$. Reduced scale tunnels have been constructed to study the flow resistance of the tunnels $[13,14]$.

Although ventilation improves the air quality inside the tunnel, it could bring excessive moisture. In the lower Yangtze River basin area in China, the air temperature rises faster than the soil temperature in spring and summer. It becomes higher than the temperature in the UUT during the late spring and summer. When the outside air is humid and is above the saturation point of the tunnel walls, the ventilation schedule will cause serious condensation. In these two seasons, the tunnels are constantly humid and wet, which makes the working environment deteriorate and increases risks to the health of workers. In addition, a higher breakdown rate of electrical and mechanical equipment in the tunnel, such as electric lights, sensors, surveillance, etc. was reported and was supposedly linked to the long exposure to the humid environment.

To our knowledge, few studies have considered the dehumidification in the UUT. The interactions among the tunnel structures, the ventilation systems, and the tunnel moisture are not well understood. This knowledge gap prohibits reasonable sizing and design of the UUT to cope with the moisture issues. In this study, a dehumidification experiment was conducted in a cable cabin of a UUT section in Suzhou, China, with the objective to identify the sources and key factors affecting the dynamic of the humidity control in a UUT. The results are valuable for providing guidance to the humidity control design of the UUT in this area.

\section{Experiment}

The test was carried out in a cable cabin in one segment of a multi-cabin UUT in the summer of 2019. Figure 1(a) shows the cross-section of the segment of the multi-cabin UUT and Fig. 1(b) shows an internal view of the cable cabin. This internal size of the cable cabin was $200 \mathrm{~m}$ long, $2.4 \mathrm{~m}$ wide, and $4.05 \mathrm{~m}$ high. The top of the segment was approximately 2.95 to $3.35 \mathrm{~m}$ below ground surface except for the middle part, which was deeper to avoid a riverbed. The top of this sunken section was $6.65 \mathrm{~m}$ below the ground surface. Although the cabin was equipped with cable conduits and supporting frame works, there was no cable deployed. The cabin could be divided into the upper part and lower part by a partition that was consisted of solid concrete slabs and grills (See Fig. 1b). At each end of the cabin, a wall with a fire door separated this cabin from the neighboring cable cabin.

As shown in Fig. 1(c), the cabin was equipped with an exhaust fan (rated at 16,650/10,130 $\mathrm{m}^{3} / \mathrm{hr}$ and total pressures of $650 / 298 \mathrm{~Pa}$ ) located on one end. To ventilate the cabin, the fan was turned on and the air would be drawn in from outside through a $1 \mathrm{~m} \times 1 \mathrm{~m}$ fire proof damper located on the other end of the cabin. For the study purpose, a dehumidifier (rated at $3,900 \mathrm{~m}^{3} / \mathrm{hr}$, cooling capacity $61.5 \mathrm{~kW}$, hereinafter referred as the fresh air dehumidifier or FAD) was installed before the fire proof damper to control the inflow humidity. The FAD dehumidified the fresh air before discharging it into the cabin via the fire-proof damper and three PVC pipes with a diameter of $200 \mathrm{~mm}$. The discharge outlets of these pipes were located at the lower part of the cabin. In addition, a ceiling type dehumidifier (rated at $1,000 \mathrm{~m}^{3} / \mathrm{hr}$ and $3.2 \mathrm{~kW}$, hereinafter referred as the CTD) was placed on the partitioning slab/grill, right below the exhaust fan. The CTD drew and dehumidified the air from the cabin at one end and discharged the air back to the cabin via a $200 \mathrm{~m}$ long $\Phi 200$ PVC pipe, which had 9 outlets (each via a T-type connector except the last one, which was a 90 degree bend) distributed evenly along the pipe. A valve was installed at each outlet to adjust the airflow rate. The air was discharged from the outlet horizontally to the upper half of the cabin except the last two. The last two air supply outlets discharged the air to the middle and lower half of the cabin.

To avoid over-cooling the cabin, the CTD used all its condensation heat to reheat the discharge air while the FAD used a part of its condensation heat to reheat the discharge air. Therefore, all heat of the CTD was released back into the cabin while only a part of the heat of the FAD was discharged into the cabin. The condensation water was discharged into the rainwater drainage wells inside the cabin, where it was pumped out of the 
Fig. 1 The tested cable cabin and its ventilation and dehumidification systems. (a) Cross section views of the tunnel and (b) photo of the tested cable cabin (only the upper half and grid are shown in the photo). (c) Dehumidification and ventilation systems. The solid dots are sensor locations for $\mathrm{T}$ and $\mathrm{RH}$ measurements. $\mathrm{FAD}=$ Fresh air dehumidifier, CTD = Ceiling Type dehumidifier
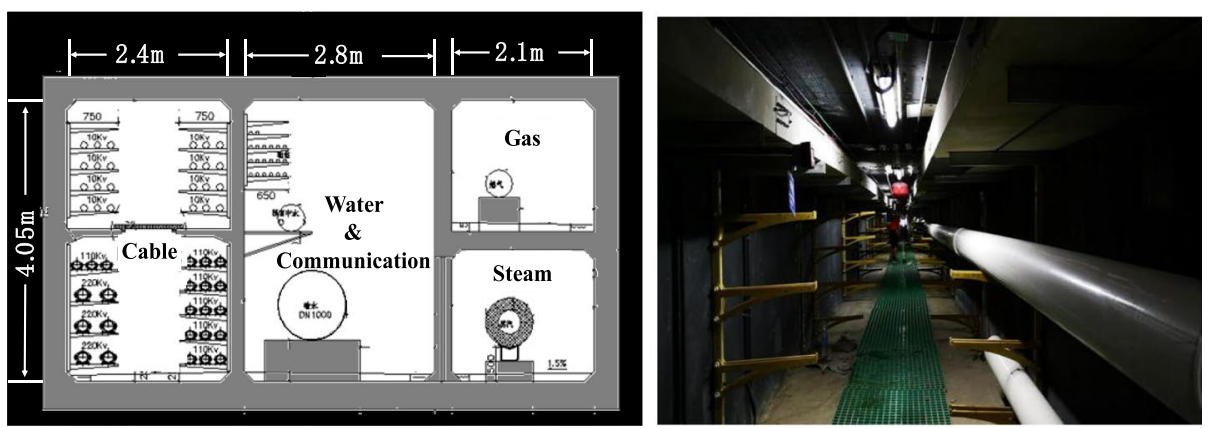

(a)

(b)

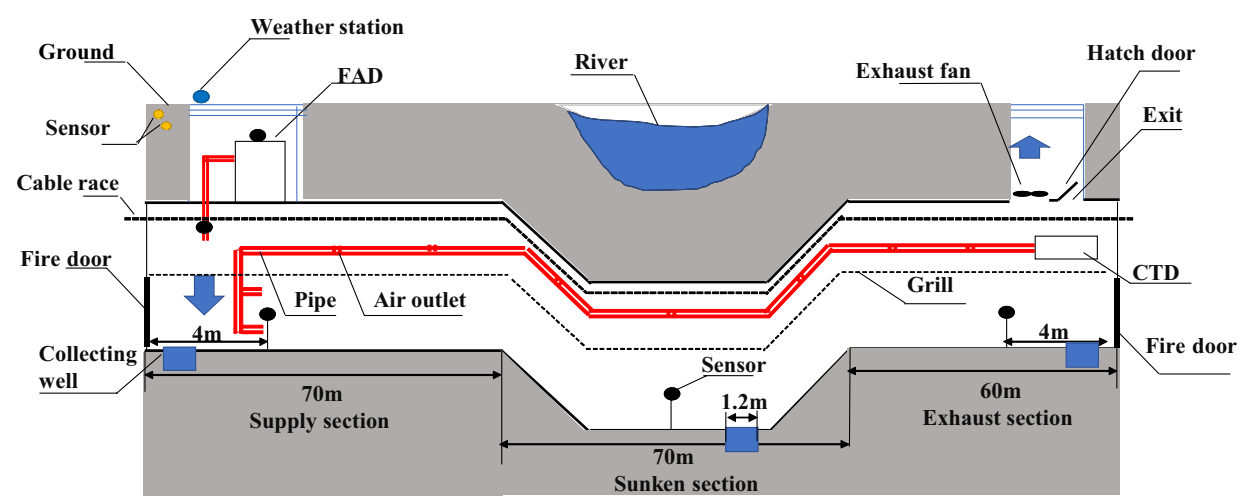

(c)

cabin to the city drainage system on the ground. There were totally three such drainage wells in the test cabin.

The lower speed of the exhaust fan was used in the test. Even so, the flow rate of the exhaust fan was greater than the supply airflow rate of the FAD. There was a square hatch door next to the exhaust fan used as the entrance to the cabin. It was kept open to compensate the difference in the airflow rates between the FAD and the exhaust fan during the experiment.

The temperature and humidity were measured at 5 locations as shown in Fig. 1(c). The first measuring location was at the inflow of the FAD. The second one was in one of the discharge pipes of the FAD. The third one was located just $1 \mathrm{~m}$ below the discharging outlet of the FAD. The fourth one was in the middle of the sunken section. The fifth one was located below the CTD unit. All the later three sensors were placed about $1 \mathrm{~m}$ above the tunnel floor. The temperature and the humidity were recorded every $4 \mathrm{~min}$ using a temperature and humidity recorder (Hangzhou Zeda U series, $\left.\mathrm{T}: \pm 0.5{ }^{\circ} \mathrm{C}, \mathrm{Rh}: \pm 3 \%\right)$. An additional weather station (T: $\pm 0.1{ }^{\circ} \mathrm{C}, \mathrm{Rh}: \%$ ) was used to collect the outdoor temperature and humidity $0.1 \mathrm{~m}$ above the ground surface, right outside the FAD room, and the soil temperature at $1 \mathrm{~m}$ and $3 \mathrm{~m}$ deep and approximately $2 \mathrm{~m}$ from the edge of the tunnel side wall. The temperature sensor was two PT1000 resistance sensors.

\section{Modeling}

For modeling purpose, the test cabin was divided into three sub-sections with equal volume: the supply section where the FAD supplied the fresh air, the sunken section, and the exhaust section where the exhaust fan was located. The possible sources of water vapor were the fresh air via the FAD, the air leakage from neighboring cabins at both ends, the vapor emission from the tunnel walls, moisture diffusion from the soil through the walls, and the evaporation from the exposed water surface. The mass balance equations for the water vapor in the three sections are as follows.

$\frac{d(\rho V C)_{11}}{d t}=(q \rho C)_{f}+\dot{m}_{\text {wall }}+\dot{m}_{e v}+\dot{m}_{d}+\frac{(q \rho C)_{\mathrm{CTD}}}{3}+(q \rho C)_{l o u}-C_{11}(q \rho)_{12}$

$\frac{d(\rho V C)_{22}}{d t}=C_{11}(q \rho)_{12}+\dot{m}_{\text {wall }}+\dot{m}_{e v}+\dot{m}_{d}+\frac{(q \rho C)_{\mathrm{CTD}}}{3}-C_{22}(q \rho)_{23}$

$\frac{d(\rho V C)_{33}}{d t}=C_{22}(q \rho)_{23}+\dot{m}_{\text {wall }}+\dot{m}_{e v}+\dot{m}_{d}+\frac{(q \rho C)_{\mathrm{CTD}}}{3}-C_{33}(q \rho)_{e x}$

where $\rho$ is the air density in the tunnel, $\mathrm{kg} / \mathrm{m}^{3} ; V$ is the volume of the test section tunnel $\left(=1,944 \mathrm{~m}^{3}\right) . C$ is the humidity of the tunnel, $\mathrm{kg} / \mathrm{kg} . \dot{m}_{\text {wall }}$ is the emission rate of the tunnel wall, kg/s. $\dot{m}_{e v}$ is the evaporation rate of open water, kg/s. $\dot{m}_{d}$ 
is the moisture diffusion from the soil through the concrete wall to the inside of the tunnel, $\mathrm{kg} / \mathrm{s} . q$ is the airflow rate, $\mathrm{m}^{3} / \mathrm{s}$. The numbers $(1,2$, and 3$)$ in the subscript represent the supply section, sunken section, and exhaust section, respectively. The subscript $i j(i, j=1,2,3)$ represents a direction from sub-section $i$ to $j$ when $i \neq j$ and the average of the $i$ section when $i=j$. For example, $C_{11}$ is the average humidity of the supply section and $q_{12}$ is the airflow rate from the supply section to the sunken section. The subscript $f$ represents the fresh air, lou represents the air leakage, and ex represents the exhaust. The subscript $d$ for $\rho, q$, and $C$ represents the CTD.

The mass balance equations for the air in the three sections are as follows.

$\frac{\mathrm{d}(\rho V)_{11}}{d t}=(q \rho)_{f}+\frac{(q \rho)_{\mathrm{CTD}}}{3}+(q \rho)_{l o u}-(q \rho)_{12}$

$\frac{d(\rho V)_{22}}{d t}=(q \rho)_{12}+\frac{(q \rho)_{\mathrm{CTD}}}{3}-(q \rho)_{23}$

$\frac{d(\rho V)_{33}}{d t}=(q \rho)_{23}+\frac{(q \rho)_{\mathrm{CTD}}}{3}-(q \rho)_{e x}$

For the CTD, there is

$\dot{m}_{C T D}=(q \rho)_{\mathrm{CTD}}\left(C_{33}-C_{\mathrm{CTD}}\right)$

where $\dot{m}_{C T D}$ is the dehumidification rate of the CTD, $\mathrm{kg} / \mathrm{s}$.

\section{Airflow rates}

The dehumidifier FAD was rated at $3,900 \mathrm{~m}^{3} / \mathrm{hr}$. However, the actual flow rate was much lower due to the additional resistance of the connection pipes, blinds, and the tunnels. The actual flow rate was calculated to be $q_{f}=1,402 \mathrm{~m}^{3} / \mathrm{hr}$, based on the velocity measurements at the three pipe outlets using an anemometer (Testo $405 \mathrm{~V} 1, \pm 0.1 \mathrm{~m} / \mathrm{s}$ or $5 \%$ of the measured value).

The leakage at both ends of the test cabin was significant. Although attempts were made to seal the leakage on the intersegments walls where the cable conduits ran through, leakage could still occur through cable conduits. In addition, there were gaps between the fire doors and the door frames. Sealing the door gaps was not possible because the test section was still subjected to mandatory routine inspection by the staff during the test. The inspection staff was asked to keep the door closed, although they often forgot to do so at the beginning of the test. The leakage was estimated by measuring the velocity at the gap using the handheld Testo anemometer and the size of the gap. When both the FAD fan and the exhaust fan were not running, the air leaked in at the supply section and leaked out in the exhaust section. The leakage rates were estimated to be $Q_{\text {lou,in }}=Q_{\text {lou, out }}=36 \mathrm{~m}^{3} / \mathrm{hr}$. When the exhaust fan and FAD fan were running, the resulting negative pressure in the cabin caused the air to leak in at both ends. The air leakage in the supply air section was measured to be $Q_{\text {lou,in }}=129.6$ $\mathrm{m}^{3} / \mathrm{hr}$. When the exhaust fan was closed and only the FAD fan was running, a positive pressure was generated in the test section and the air leaked out at both ends. The outgoing air leakage was measured to be $Q_{\text {lou,in }}=12.96 \mathrm{~m}^{3} / \mathrm{hr}$ in the supply section. The air leakage at the exhaust fan was not particularly measured, but the value of $Q_{f, \text { out }}$ was calculated from the balance of airflow in the cabin.

\section{Dehumidification rate of the CTD}

The actual moisture removal rate of a dehumidifier depends on the status of the inflow air. Because the air in the UUT was relatively stable in terms of temperature and humidity, the CTD was assumed to have worked at a steady moisture removal rate. The dehumidification rate of the dehumidifier was measured twice by measuring the amount of the condensed water and the two repeat measurements showed that the value was relatively stable at $\dot{m}_{C T D}=3.33 \mathrm{~kg} / \mathrm{hr}$.

\section{The evaporation of open water surface}

There was a $0.2 \mathrm{~m}$ wide and $0.1 \mathrm{~m}$ deep drainage channel at the foot of the side wall that separated the test cabin with the water $\&$ communication cabin. This channel was used to drain water spill that might appear in the UUT. This could be due to the maintenance use of water or seepage through the walls. In the supply section, the storm water drainage pipe was not directly connected to the drainage well. Instead, the storm water was discharged to the drainage channel at a point close to the well. However, in heavy raining events, the water could easily overflow the channel causing only part of the water flowing towards the well. The rest flowed in the other direction towards the sunken section. This caused prolonged lingering of the water in the cabin. During the test period, the drainage well was filled with water. And the drainage channel was partially wet or filled with water. The evaporation of water in the wet channel and the wells was an important moisture source.

The fundamental behind the water evaporation is rather simple and straightforward. However, due to different ways in accounting for the influence of wind speed and air temperature and the inconsistency in meteorological data collection methods and standard, there are more than 100 methods with similar structure for the calculation of evaporation rate [15]. The basic form, proposed by Dalton in 1802, states that the evaporation rate is proportional to the water vapor pressure difference.

$\dot{m}_{e v}=\mathrm{f}(u)\left(e_{s}-e\right) A_{e v}$ 
where $A_{e v}$ is the evaporation area, $\mathrm{m}^{2} ; e_{S}$ is the partial pressure of saturated water vapor, $\mathrm{kPa} ; e$ is the partial pressure of saturated water vapor in the air, $\mathrm{kPa} . \mathrm{f}(\mathrm{u})$ is the convective mass transfer coefficient, which is a function of wind speed $(u, \mathrm{~m} / \mathrm{s})$ at the surface. Earlier work used a linear function of wind speed for this coefficient $[16,17]$, while nonlinear relation was also used $[18,19]$. In this study, a set of correlations proposed by Min and Zhang [20] was used:

$\mathrm{f}(u)=\left\{\begin{array}{c}0.21+0.055 u^{1.25}(u \leq 1 \mathrm{~m} / \mathrm{s}) \\ 0.18+0.085 u(1<u<4 \mathrm{~m} / \mathrm{s}) \\ 0.149 u^{1-0.0612(u-4)^{0.5}}-0.076(u \geq 4 \mathrm{~m} / \mathrm{s})\end{array}\right.$

The wind speed in the tunnel is calculated as follows:

$u=\frac{q_{f}+q_{\text {lou }}}{3600 \rho A_{t}}$

where $A_{t}$ is the cross-sectional area of the tunnel, $m^{2}$. The partial pressure of saturated water vapor, $e(\mathrm{kPa})$ is calculated by Tetens formula [21]:

$e=0.61078 \times R h \times e^{17.2694 \times \frac{T}{T+237.3}}$

where $T$ is the temperature, ${ }^{\circ} \mathrm{C} ; R h$ is the relative humidity in the air, \%.

The evaporation area is the sum of the three well areas plus the drainage channel area. The drainage well each measured $1.2 \mathrm{~m}$ by $1.2 \mathrm{~m}$. The wet area of the drainage channel was estimated to be $8 \mathrm{~m}^{2}, 14 \mathrm{~m}^{2}$, and $2 \mathrm{~m}^{2}$ in the supply section, sunken section, and exhaust section, respectively.

\section{Moisture diffusion from the soil}

The moisture diffusion from the soil to the tunnel space is driven by the difference of vapor pressure between the soil space and the tunnel space.

$\dot{m}_{d}=A_{w} \cdot \frac{e_{\text {soil }}-e}{R_{0}}$

where $A_{w}$ is the wall area, $\mathrm{m}^{2} ; e_{\text {soil }}$ is the water vapor pressure in the soil outside the tunnel wall, $\mathrm{kPa} ; R_{0}$ is the total resistance, $\left(\mathrm{m}^{2} \bullet \mathrm{kPa} \bullet \mathrm{s}\right) / \mathrm{kg}$. The moisture concentration in the soil is considered saturated because of the high water table in this region. The saturated moisture concentration in the soil is dependent on the soil temperature.

Compared with the other sources, however, the diffusion term was negligible in the studied period. First, the resistance was large due to the thick concrete wall (300 to $350 \mathrm{~mm}$ ) and the use of vapor-proof membrane at the outer layer of the concrete wall. Second, the vapor pressure difference between the inside and outside of the tunnel was believed to be small because the temperatures of the soil and the tunnel air were close (Readers can refer to Fig. 2). Assuming a temperature difference of 5 degrees, a penetration coefficient of $4.81 \times 10^{-12} \mathrm{~kg} /(\mathrm{m} \cdot \mathrm{s} \cdot \mathrm{Pa})$ for the concrete [22], and a penetration coefficient of $2.58 \times 10^{-8} \mathrm{~kg} /$ ( $\mathrm{m} \cdot \mathrm{s} \cdot \mathrm{Pa}$ ) for the $1.5 \mathrm{~mm}$ PE membrane [23], the diffusion rate is estimated to be about $0.007 \mathrm{~kg} / \mathrm{hr}$ through the 1,770 $\mathrm{m} 2$ concrete walls. These value is much smaller than those of the other sources, which are in the order of $1 \mathrm{~kg} / \mathrm{hr}$ as shown later. As a result, the moisture diffusion through the walls is neglected in the analysis.

\section{Moisture emission from the wall}

Water is used during the mixing of the cement. Naturally there is water residual in the cement. This water residual can be an important source of water vapor at the initial stage. However, the emission rate is expected to gradually decrease with time and finally reach a steady state when the emission balances the adsorption [24, 25]. In the long run, the concrete walls of the tunnel can be viewed as a buffering reservoir that regulates the dynamics of the moisture content in the tunnel through adsorption and desorption. In the building applications, terms, such as the moisture buffer value, moisture buffer capacity etc. have been used to quantify the effect on indoor humidity [26]. In this study, however, it is difficult to differentiate the emission of the residual water inside the concrete from the desorption/sorption occurring at the surface. Therefore, the emission rate is defined as the overall net mass transfer rate between the air phase and the tunnel walls. The tunnel walls are a sink source if the emission rate is negative. In the earlier work, the moisture emission from concrete surface was analogous to the evaporation of water surface. The rate was assumed to be dependent on the vapor pressure difference between the air and the concrete surface [27]. In this study, the formula is modified by introducing a coefficient $\beta$ :

$\dot{m}_{\text {wall }}=0.313 \beta A_{\text {wall }}\left(e_{S w}-e\right)(0.253+0.216 u)$

where $\beta$ is the correction factor; $A_{\text {wall }}$ is the total surface area of the tunnel walls, $m^{2}$; and $e_{S w}$ is the saturated vapor pressure on concrete surface, $\mathrm{kPa}$.

Equations (1-13) describe the model for the dynamic balance of moisture in the cabin. Due to the lack of data on $\beta$, the model was fit to the experimental data using the least sum of squares for the correction coefficient $\beta$. The results were analyzed to discuss on the moisture emission characteristics from the cabin wall. 
Fig. 2 Measured temperature and humidity data during the test period. The discharge temperature and humidity data were measured at the discharge of the FAD. The soil temperatures were measured $3 \mathrm{~m}$ below the ground surface. The outdoor temperature and humidity data were measured $0.1 \mathrm{~m}$ above the ground surface

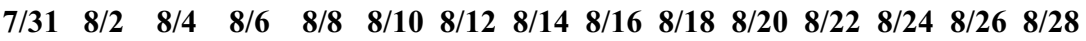
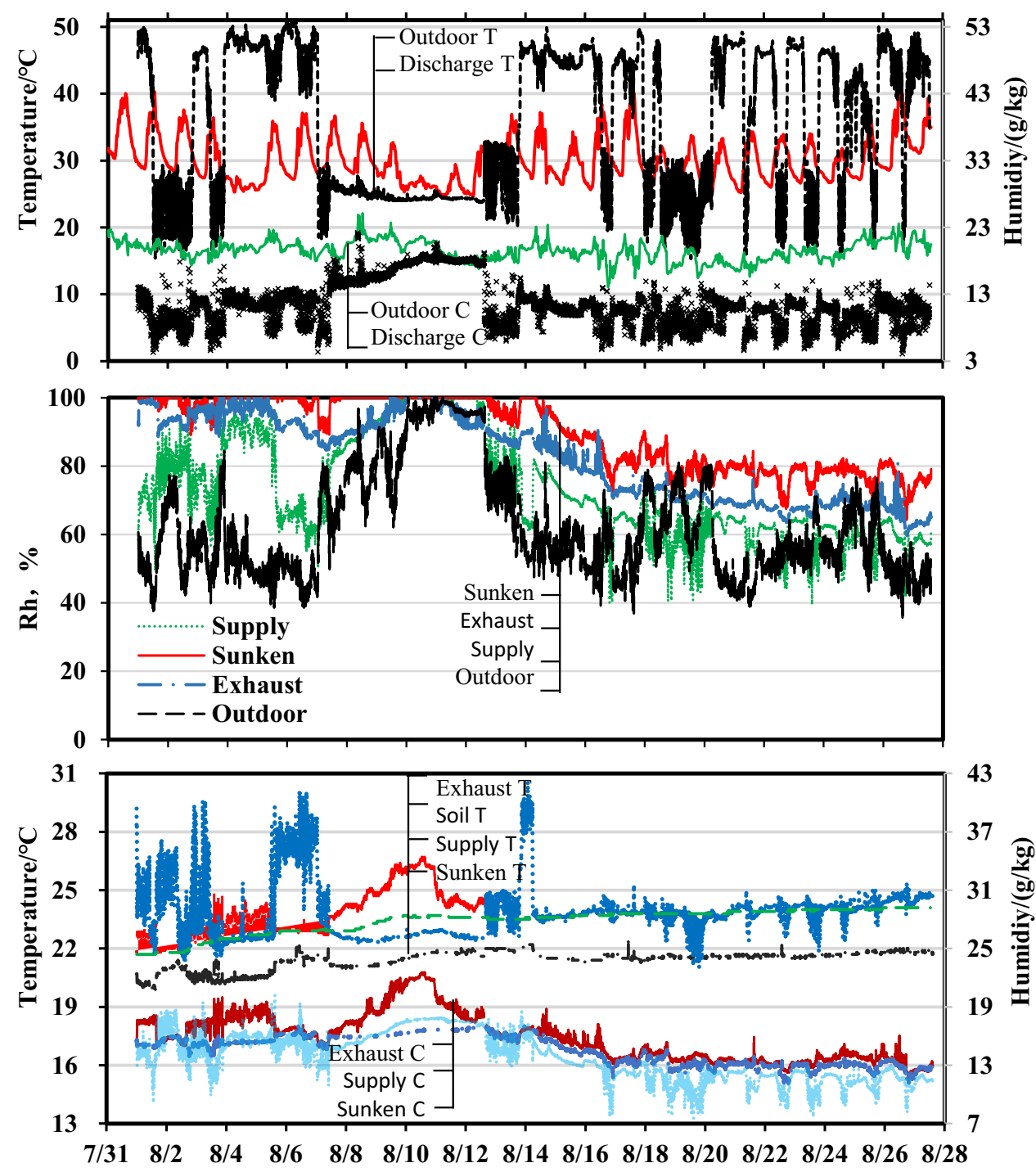

\section{Result and discussion}

\section{Measured data during dehumidification}

Figure 2 shows the measured temperatures and humidity inside and outside the tunnel together with the soil temperatures during the dehumidification test from July 31 to August 28, 2019. The CDT was on throughout the test. The FAD was turned off for maintenance from August 7 to 12. This area was hit by a typhoon on August 10. On August 16, the exhaust fan was found broken down.

During the test period, the outdoor temperature fluctuated between $28{ }^{\circ} \mathrm{C}$ and $40{ }^{\circ} \mathrm{C}$. There were days when the temperature remained above $30{ }^{\circ} \mathrm{C}$, even at night. The outdoor humidity varied around 15 to $22 \mathrm{~g} / \mathrm{kg}$ during this period. It reached the highest (about $22 \mathrm{~g} / \mathrm{kg}$ ) right before August 10 due to the earlier influence of the typhoon. Within a few days after the typhoon hit on August 10, the temperature decreased to around $25{ }^{\circ} \mathrm{C}$. The humidity declined as well. After that, the outdoor temperature recovered to be around $32{ }^{\circ} \mathrm{C}$ and the humidity remained about $18 \mathrm{~g} / \mathrm{kg}$. The outdoor relative humidity was around $55 \%$ during this period expect during the typhoon event when it rose to the saturation point (100\%).

Inside the tunnel, the temperatures the humidity displayed two different patterns before and after August 12. There was not a consistent pattern before August 12. The temperature of the supply section fluctuated considerably with maximum value as high as $30^{\circ} \mathrm{C}$. The temperature of the sunken section changed smoothly and was consistently about $2.5^{\circ} \mathrm{C}$ lower than the soil temperature $3 \mathrm{~m}$ below the ground surface except on August 2 and 6 when the difference was reduced to $1 \sim 1.5^{\circ} \mathrm{C}$. The temperature of the exhaust section also changed smoothly but peaked during the Typhoon incidence. The sunken section was almost saturated with relative 
humidity close to $100 \%$ while the exhaust section was close to saturation with relative humidity in the range between 90 and $100 \%$. The supply section was relatively drier, but the humidity fluctuated considerably. It can be noted that the supply section was influenced mostly by the discharge air while the exhaust section had strong influence of the outdoor air. After August 12, the consistent dehumidification effect started to appear. Our interview with the management team revealed that before August 12, the ignorant inspectors had often left the fire doors open during their daily routine inspections although these doors were supposed to be closed all the time. Such mistake was no longer repeated after these inspectors were properly informed of the ongoing test. However, these mistakes have made it impossible to understand the airflow pattern in the test sections before August 12. In addition, strong air exchange between the tunnel and the outside through the opened hatch door was evident during the typhoon event as both the temperature and humidity in the exhaust section rose close to those of the outdoor values. Such strong wind-related interference was also difficult to quantify. Finally, the tunnel, especially the sunken section, was experiencing the evaporation of the previously condensed water drops. And it was difficult to determine the amount of condensation. Therefore, the data before August 12 was excluded from the modeling analyses. By August 12 , the tunnel had been found dry with no visible condensation and the humidity in the cabin started to decrease. The humidity decreased to about 12 to $13.5 \mathrm{~g} / \mathrm{kg}$ on August 16 and then stabilized thereafter although the outdoor humidity had been consistently varying between $15 \mathrm{~g} / \mathrm{kg}$ to $25 \mathrm{~g} / \mathrm{kg}$ with an average of about $19.6 \mathrm{~g} / \mathrm{kg}$. Although the temperature in the sunken section was still about $2.5^{\circ} \mathrm{C}$ lower than those of the other two sections, there was no considerable fluctuations in the temperature and humidity. Only the supply section had fluctuations, which was associated with the fluctuating temperature of the discharging air from the FAD. At steady state, the relative humidity was about $60 \%, 70 \%$, and $80 \%$ in the supply section, exhaust section, and sunken section, respectively. It took about 4 days for the dehumidification systems to reach this state from saturation.

\section{Moisture emission rate of concrete surface}

\section{Correction coefficient $(\boldsymbol{\beta})$}

The coefficient $\beta$ was obtained for the data starting from August 13. Data before this date was avoided due to considerable uncertainties as mentioned in previous section. The data at August 13, 15, 17, 19, and 21 were used to fit for $\beta$. The values, together with the comparison between the model and the measurement are shown in Fig. 3.

With the correction value of $\beta$, the model agreed well with the measurement both in magnitude and trend for the supply section. The agreement was also good for the other two sections at the earlier days. In the later days, the model predicted larger fluctuations than the measured values. The reason maybe that the actual flow rate from the supply section to the exhaust section was less than the modeled value due to the breakdown of the exhaust fan. The less flow rate would have made the sunken and exhaust humidity values less sensitive to the FAD discharge and hence less fluctuations. Figure 3 shows that on the 21st of August, the simulation agreed with the measurement in magnitude but differed in fluctuation.

The correction coefficient $\beta$ introduced for the moisture emission from the tunnel wall is an important parameter reflecting the saturation status of the wall. The $\beta$ value varies as the status of the wall changes with time. The dynamics of the correction coefficient $\beta$ is of more interest. Figure 4 plots the variations of $\beta$ with time. Note that the fitting has produced negative value of $\beta$ at some dates, especially at the later days in the supply section. Physically negative $\beta$ would mean that the wall had become a sink and started to take moisture from the air. The supply section had been continuously subjected to the dry air from the FAD. The $\beta$ line leveled off 4 days of dehumidification. In the sunken and exhaust sections, things were different. On August 16, the exhaust fan was found broken down. Without the pull of the exhaust fan, there could be much less airflow from the inlet section to the exhaust section and more air leaked out. This change may have caused the $\beta$ values for these two sections more variable than that for the supply section. In the sunken section, the $\beta$ value declined in general but at a slower rate. In the exhaust section, the $\beta$ value decreased first but then increased after August 19.

Due to the failure of exhaust fan and the resulting insufficient ventilation airflow, there were more uncertainties associated with the sunken and exhaust sections. This exhaust section was subjected to the influence of the neighboring section and the outside air because the hatch door was open during the test. The factor that the mean value of the correction coefficient $\beta$ of the sunken section was greater than those of the supply and exhaust sections indicates that the sunken section did not have a good ventilation effectiveness. The hotter and dryer air would flow at the top of the sunk section and failed to mix with the air at the bottom. Therefore, the dehumidification was slower and less efficient.

It is found that an exponential function can reasonably describe the dynamic changes of this coefficient. The dynamics of the beta could be well represented by the following set of equations.

$\beta_{1}=0.1 e^{-0.03585 t}-0.00492$

$\beta_{2}=0.05 e^{-0.00711 t}+0.01$ 

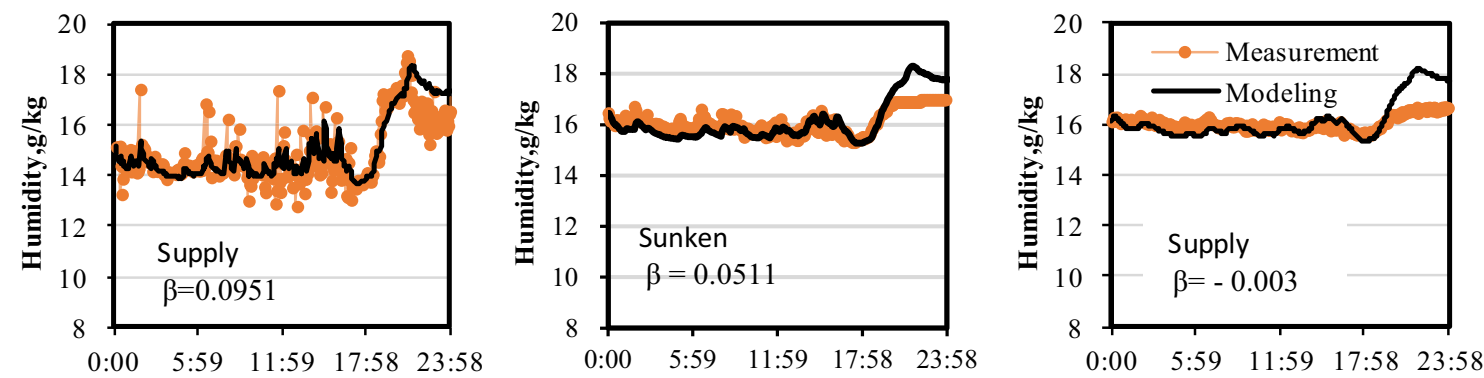

(a) August 13
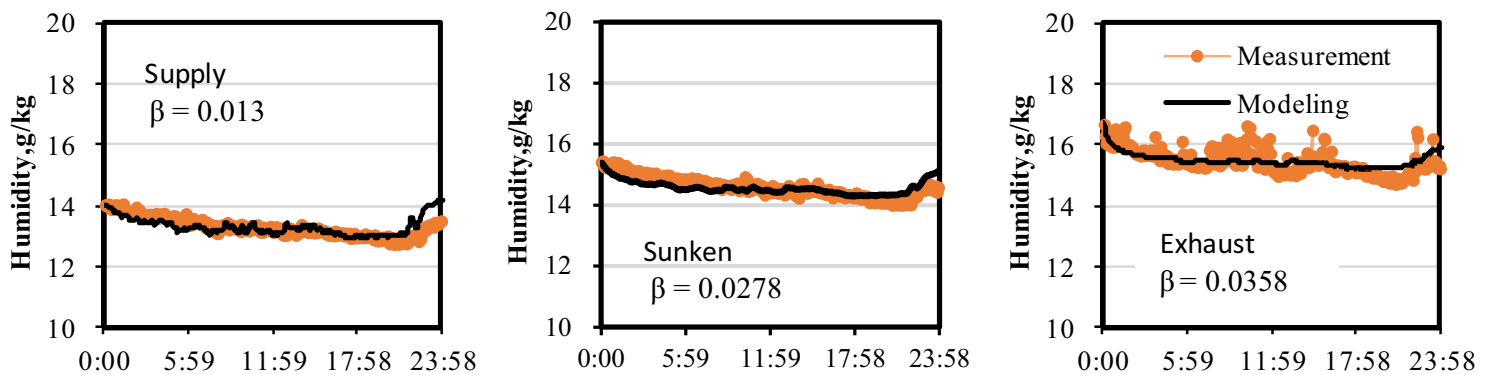

(b) August 15
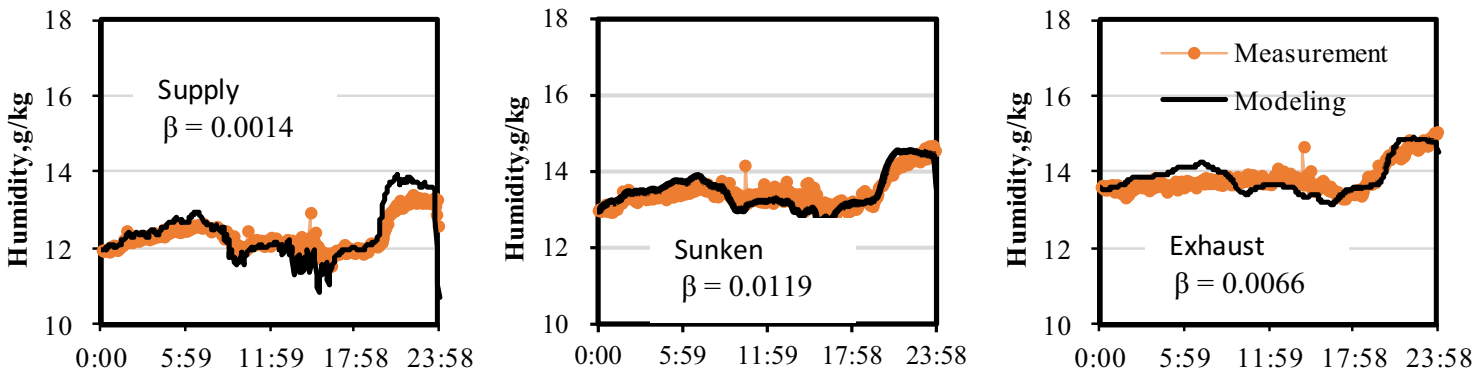

(c) August 17
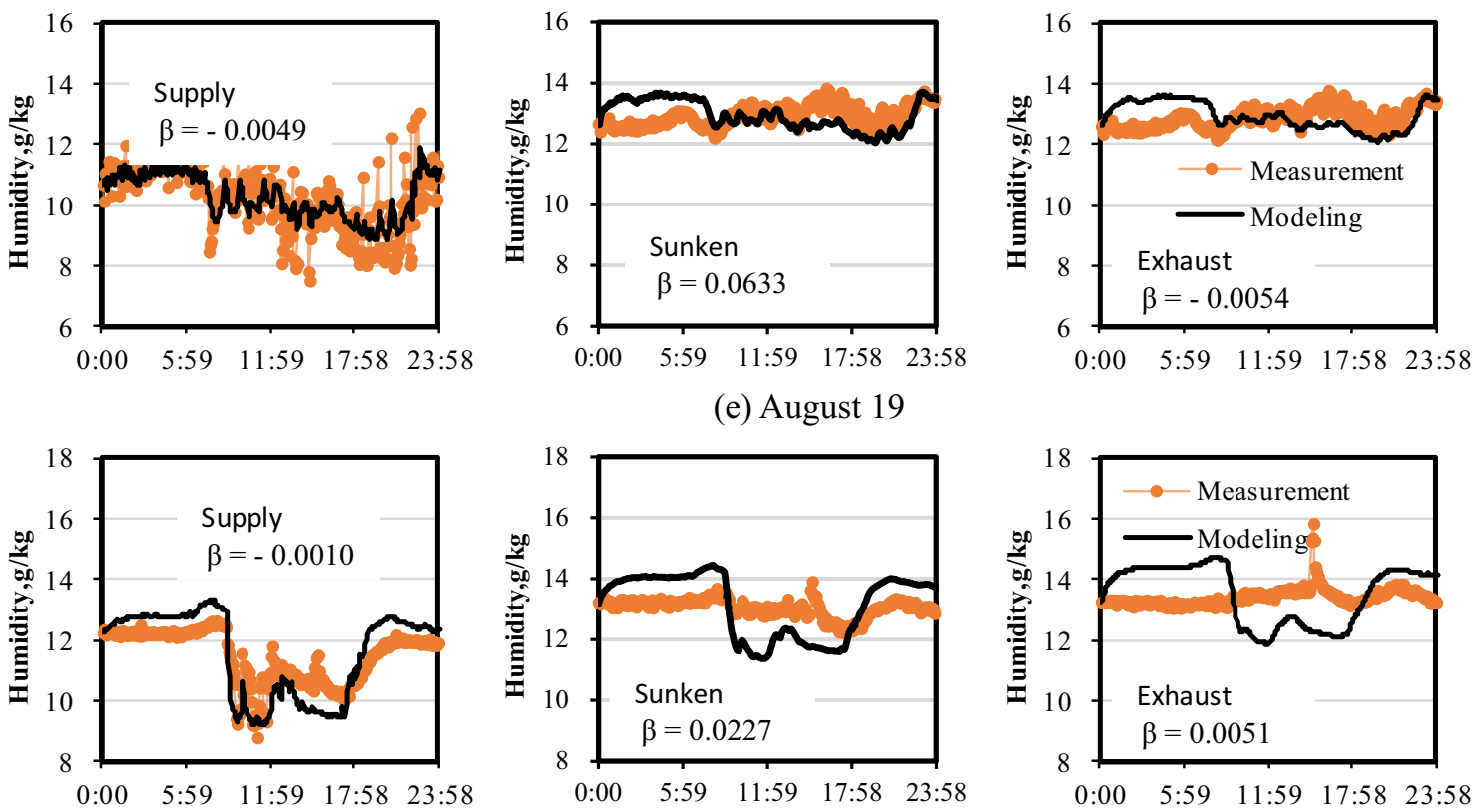

(e) August 21

Fig. 3 Comparison of humidity between measurement and model prediction at 5 days 


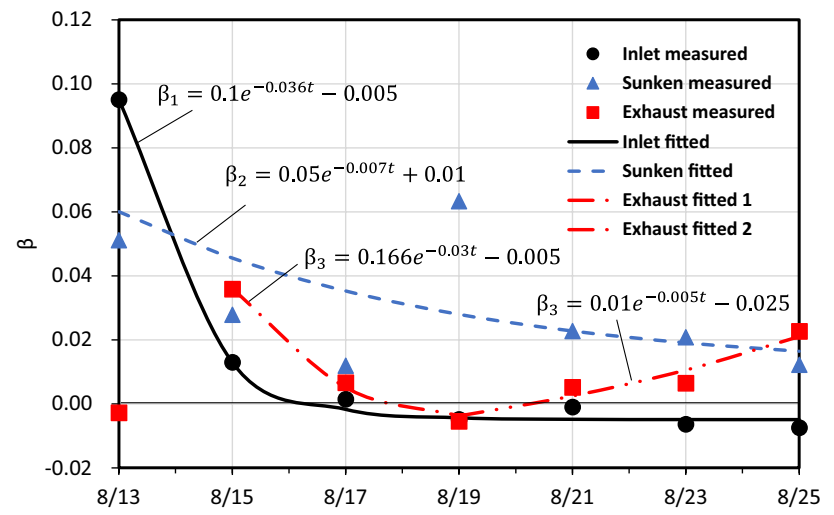

Fig. 4 The dynamic change of the correction coefficient for the emission rate of moisture from concrete surface

$\beta_{3}=\left(\begin{array}{l}0.1662 e^{-0.02916 t}-0.005 \text { Before Aug. 19 } \\ 0.00978 e^{-0.00538 t}-0.025 \text { After Aug. 19 }\end{array}\right)$

where $t=0(\mathrm{~min})$ at 0:00 a.m. on August 13, 2019. For the supply section, the fitting process was performed assuming a stable value of -0.005 and the line was forced to intercept the $y$ axis at 0.1 . For the exhaust section, the first data point was not considered and the two segments before and after August 19 were fitted separately. The supply section was subjected to a continuous dehumidification. It can be concluded that for a continuous emission process, the dynamics of the emission rates in reference to free water evaporation experienced an exponential changing rate.

Several studies also reported exponential decreasing rate of moisture emission from concrete surface compared with the free water evaporation. For example, Manal [28] studied the evaporation and surface drying conditions of concrete in the Arabian Gulf climate and found that the time constant of the exponential function are related to the concrete materials. Zhang studied the influence of initial water ratio in the mixing of cement on the moisture emission rate [29]. The ratio of emission rate to the free water evaporation rate was also expressed as an exponential function.
Fig. 5 Comparison of simulated humidity and measured humidity in the tunnel from August 13 to 26
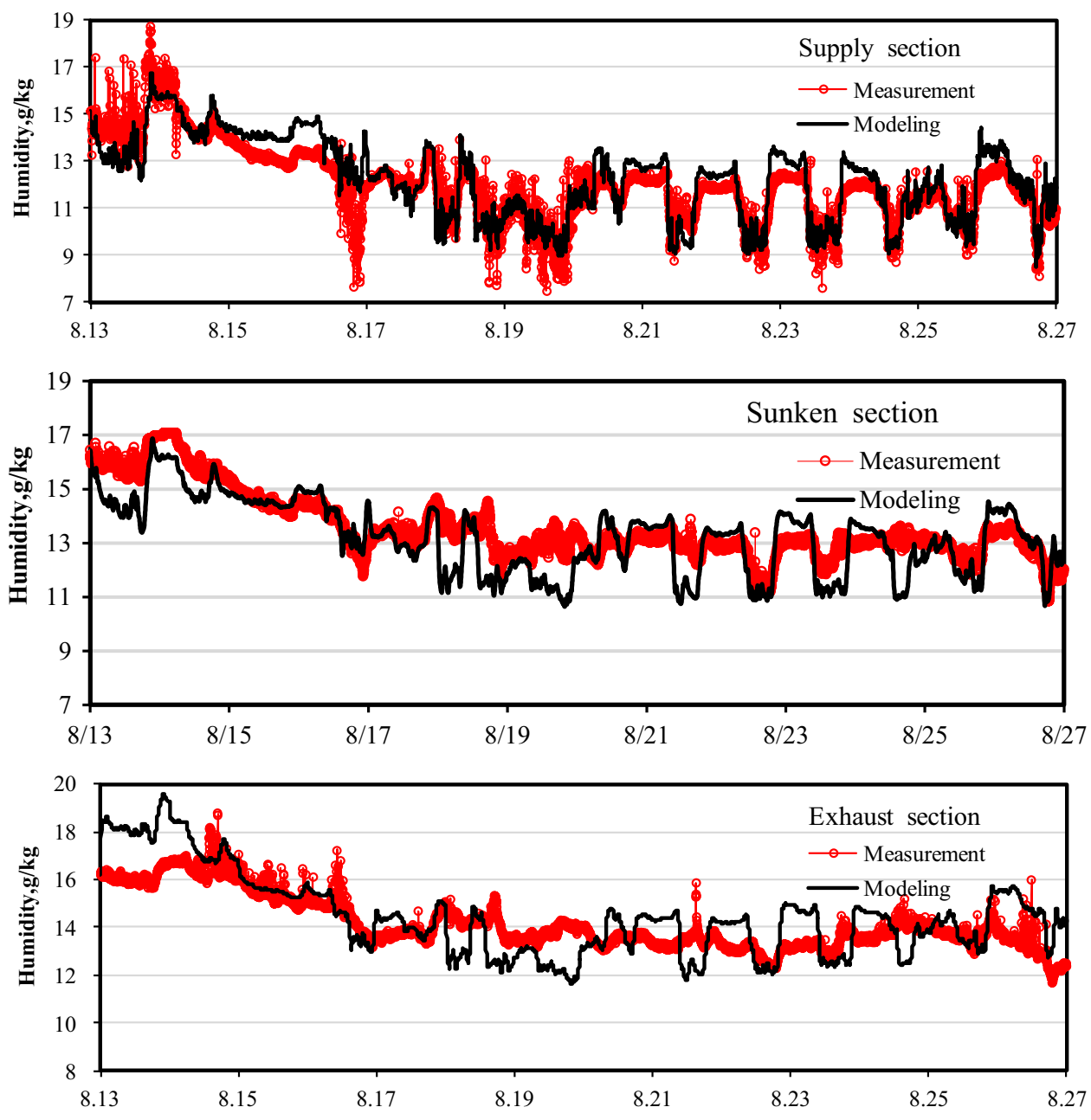
Table 1 Index of ASTM criteria in evaluating the agreement between the model and the measurement

\begin{tabular}{lllllll}
\hline Sections & $\begin{array}{l}\text { Correlation Coef- } \\
\text { ficient }\end{array}$ & Regression slope & $\begin{array}{l}\text { Regression } \\
\text { intercept }\end{array}$ & NMSE & Fractional bias & $\begin{array}{l}\text { Fractional bias based } \\
\text { on variance }\end{array}$ \\
\hline ASTM & $\geq 0.9$ & $0.75 \sim 1.25$ & $\leq 25 \%$ & $\leq 0.25$ & $\leq 0.25$ & $\leq 0.5$ \\
Supply & 0.75 & 0.83 & 1.9 & 0.01 & 0.01 & 0.08 \\
Sunken & 0.59 & 0.7 & 4.2 & 0.005 & 0.03 & 0.16 \\
Exhaust & 0.56 & 0.5 & 6.98 & 0.007 & 0.02 & 0.77 \\
\hline
\end{tabular}

\section{Model validation}

With Eqs. (1-16), the model predicted the average humidity in the tunnel from August 13 to 26 with reasonable accuracy as shown in Fig. 5. Both the trend and the fluctuations were predicted for the supply section. For the sunken section, a relatively larger discrepancy in the fluctuations can be observed. In the exhaust section, the model predicted the trend well but not so well the fluctuations. Table 1 gives an evaluation of the model performance based on the ASTM criteria [30]. Both the fractional bias and normalized mean square error (NMSE) were close to zero. The correlation coefficients were greater than 0.5 but lower than the ASTM criterion indicating that the model was not perfect but could explain most of the variations of the measured data. The statistical performance measures also show that the agreement was best for the supply section. Although the model has missed fluctuations in the sunken and exhaust sections, it has predicted the average humidity of the last six days in all three sections with the largest error of $3.4 \%$ in the exhaust section.

During this period (from August 13 to 26), the average emission rate of moisture from the exposed water surface was $4.195 \mathrm{~kg} / \mathrm{hr}$, or $0.148 \mathrm{~kg} /\left(\mathrm{hr} \cdot \mathrm{m}^{2}\right)$. The tunnel concrete wall surface acted as a buffering reservoir. Its initial contribution was as high as $17.171 \mathrm{~kg} / \mathrm{hr}$, or $0.008 \mathrm{~kg} /\left(\mathrm{hr} \cdot \mathrm{m}^{2}\right)$ indicating that it can be a significant source at the beginning of the dehumidification process and a sink when the air humidity increases after a balance is reached. These values suggest that the dynamic regulation of the moisture in the tunnel by the concrete walls cannot be ignored due to its large surface area. In particular, this regulation has to be considered in the design of dehumidification systems when an intermittent dehumidification strategy is adopted.

\section{Conclusions}

The dynamic moisture balance of an underground utility tunnel (UUT) was studied with the objective to understand the influencing factors on the humidity control, which is important in wet seasons for a healthy and safe tunnel environment. A dehumidification experiment was carried out in a $200 \mathrm{~m}$ long cable cabin in a UUT in a city of eastern China in August. The corresponding mathematical model for the moisture was developed and validated by the experimental data. The following conclusions can be made.

The major moisture sources to be considered in the design of a UUT section are the ventilated airflow from outside, the evaporation from the exposed water, and the concrete walls. In general, the source strength of ventilation depends on the climate and the ventilation schedules. The evaporation from exposed water surfaces depends on the exposed area and the targeted relative humidity of the cabin. The concrete enclosure is an important source that regulates the dynamics of the moisture content. It can be a significant source at the beginning of the dehumidification process and a sink when the air humidity increases after a balance is reached.

In this studied region, the ventilation source has seasonality and is the dominant source. The humidity in the cabin can be controlled by controlling the humidity of the incoming air from the ventilation system. The average emission rate from the exposed water surface was estimated to be $4.195 \mathrm{~kg} / \mathrm{hr}$ as the final the relative humidity in the cabin reached 60 to $80 \%$. This emission rate could be reduced by minimizing exposed water surface area through measures such as covering the drainage channel and wells. The initial emission rate of the concrete walls was as high as $17.171 \mathrm{~kg} / \mathrm{hr}$. The moisture emission from the concrete wall can be analogous to the free water evaporation using a correction coefficient. The correction coefficient was found to decrease exponentially during a continuous dehumidification process.

In addition to the identified internal and external moisture sources and their implications to the construction and operations of the tunnels, the study also indicates that the current tunnel design will need to consider spaces for the dehumidification systems. Further studies may consider a holistic solution that includes all cabins in the same segment. Some cabins may have strong heat sources that may affect the design strategies. In addition, the future studies may consider the optimization of the ventilation and dehumidification strategy to achieve energy efficiency. 


\section{References}

1. Qian Q (2016) Present state, problems and development trends of urban underground space in China. Tunn Undergr Space Technol 55:280-289

2. Cano-Hurtado JJ, Canto-Perello J (1999) Sustainable development of urban underground space for utilities. Tunn Undergr Space Technol 14(3):335-340

3. GB50838 (2015) Technical specification for Urban Utility Tunnel Engineering. Ministry of Urban and Rural Development, China

4. Yang C, Peng F (2016) Discussion on the Development of Underground Utility Tunnels in China. Procedia Engineering 165:540-548

5. Canto-Perello J, Curiel-Esparza J (2001) Human factors engineering in utility tunnel design. Tunn Undergr Space Technol 16(3):211-215

6. Wang T, Tan L, Xie S (2018) Development and applications of common utility tunnels in China. Tunn Undergr Space Technol 76:92-106

7. Luo Y, Alaghbandrad A, Genger TK (2020) History and recent development of multi-purpose utility tunnels. Tunn Undergr Space Technol 103:103511

8. CSRME (2020) China urban underground space development blue book (public edition). Chinese Society for Rock Mechanics and Engineering(CSRME)

9. Curiel-Esparza J, Canto-Perello J (2005) Indoor atmosphere hazard identification in person entry urban utility tunnels. Tunn Undergr Space Technol 20(5):426-434

10. Liu Y, Xiao Y, Augenbroe G (2018) The formation of multisteady-states of buoyancy ventilation in underground building. Tunn Undergr Space Technol 82:613-626

11. Zhang P, Lan H (2020) Effects of ventilation on leakage and diffusion law of gas pipeline in utility tunnel. Tunn Undergr Space Technol 105:103557

12. Mi H, Liu Y, Jiao Z (2020) A numerical study on the optimization of ventilation mode during emergency of cable fire in utility tunnel. Tunn Undergr Space Technol 100:103403

13. Li S, Liu X, Wang J (2019) Experimental reduced-scale study on the resistance characteristics of the ventilation system of a utility tunnel under different pipeline layouts. Tunn Undergr Space Technol 90:131-143

14. Costantino A, Musto M, Rotondo G (2014) Numerical Analysis for Reduced-scale Road Tunnel Model Equipped with Axial Jet Fan Ventilation System. Energy Procedia 45:1146-1154
15. Majidi M, Alizadeh A, Farid A (2015) Estimating Evaporation from Lakes and Reservoirs under Limited Data Condition in a Semi-Arid Region. Water Resour Manage 29(10):3711-3733

16. Wang L, Kisi O, Zounemat-Kermani M (2017) Pan evaporation modeling using six different heuristic computing methods in different climates of China. J Hydrol 544:407-427

17. Paily P, Macagno E, Kennedy J (1974) Winter-regime surface heat loss from heated streams. NASA Research report. United States. https://www.osti.gov/biblio/7179276-winter-regime-surface-heatloss-from-heated-streams-research-report. Accessed 16 Sep 2021

18. Lurie M, Michailoff N (2002) Evaporation from Free Water Surface. Ind Eng Chem 28:245-349

19. Powell RW, Griffiths E (2020) The evaporation of water from plane and cylindrical surfaces. Trans Inst Chem Eng 13:175-198

20. Min Q, Zhang W (2003) Study on calculation method of water surface evaporation of reservoir. Hydropower 05:35-40

21. Murray FW (1967) On the Computation of Saturation Vapor Pressure. J Appl Meteorol 6:203-204

22. Wang Y, Ma C, Liu Y, Wang D, Liu J (2018) Effect of moisture migration and phase change on effective thermal conductivity of porous building materials. Int J Heat Mass Transf 125:330-342

23. Slanina P, Silarova S (2009) Moisture transport through perforated vapour retarders. Build Environ 44:1617-1626

24. Saliba J, Rozière E, Grondin F (2011) Influence of shrinkagereducing admixtures on plastic and long-term shrinkage. Cement Concr Compos 33(2):209-217

25. Berhane Z (1984) Evaporation of Water from Fresh Mortar and Concrete at Different Environmental Conditions. Journal Proceedings 81(6):560-565

26. Zhang M, Qin M, Rode C (2017) Moisture buffering phenomenon and its impact on building energy consumption. Appl Therm Eng $124: 337-345$

27. Uno PJ (1998) Plastic shrinkage cracking and evaporation formulas. ACI Mater J 95(4):365-375

28. Al-Fadhala M, Hover KC (2001) Rapid evaporation from freshly cast concrete and the Gulf environment. Constr Build Mater 15(1):1-7

29. Qianqian Z, Ya W (2015) Study on Evaporation Rate of Concrete Surface during Plastic Stage. J Buld Mater (18): 128-132 (Chinese)

30. ASTM F5157 (1997) Standard Guide for Statistical Evaluation of Indoor Air Quality Models, America Society of Testing and Materials, : West Conshohocken, PA. p 4 